REGUERA, Andrea. El mundo relacional de Juan Manuel de Rosas: un análisis del poder a través de vínculos y redes interpersonales. Bernal: Universidad Nacional de Quilmes Editorial, 2019.

\title{
Resenha
}

\section{A construção da política rosista a partir das relações sociais estabelecidas}

O livro da historiadora Andrea Reguera analisa a construção do poder de Juan Manuel de Rosas a partir da trama de relações interpessoais que atravessaram sua vida e a política adotada entre 1829-1833 e 1835-1852, quando assumiu o cargo de governador da província de Buenos Aires após ser eleito pela Sala de Representantes nos dois períodos. Utilizando-se, principalmente, de correspondências pessoais de Rosas, Reguera destaca a busca pela subjetividade do indivíduo na construção das relações constitutivas e dissolutivas a fim de compreender o jogo de poder presente nelas e os limites entre o público e o privado.

Organizada em três partes, a obra conta com sete capítulos. Na primeira parte, a análise das relações sociais passa pela família de Rosas e a construção de sua riqueza econômica; na segunda parte, composta por três capítulos, Reguera discorre sobre a vida política de Rosas no primeiro governo (1829-1832), durante o período em que esteve distante de Buenos Aires (1833-1834) e no segundo governo (1835-1839); a riqueza patrimonial dos legisladores e o poder dos vínculos são temas desenvolvidos na terceira parte. A autora coloca o período de 1840-1852 como sin gobernador devido aos problemas sobre a posse do cargo de governador: entre renúncias e readmissões, Rosas reassume o cargo em 1842 como "governador proprietário" até 1852, quando de sua deposição. Após a conclusão da obra, as genealogias das principais famílias que compuseram a vida pessoal de Rosas se encontram disponíveis.

Juan Manuel José Domingo Ortiz de Rosas nasceu na província de Buenos Aires em 30 de março de 1793 e faleceu em Southampton, Inglaterra, em 14 de março de 1877. Conhecido pela expressão Restaurador de las Leyes a partir de 1833, cresceu em uma 
família de importantes fazendeiros, porém conseguiu acumular uma riqueza pessoal adquirindo grandes extensões de terra. ${ }^{1}$ Sua trajetória política foi marcada pela aproximação com fazendeiros, comerciantes e militares, bem como a conquista de influência pessoal dentro e fora do âmbito político e líder do Partido Federal.

O contato com diversos e importantes grupos sociais de Buenos Aires e das províncias no interior fez com que em 1829, após o fracasso de projetos de organização nacional e um cenário de crise política intenso, Rosas fosse eleito governador de Buenos Aires com a posse das Facultades Extraordinárias e, no segundo mandato em 1835, com a Suma de Poder Publico, recurso legal que conferia amplos poderes ao governador. Esses aparatos, previstos pela Sala de Representantes, seriam utilizados em tempos de crise para a garantia da ordem e, diante do cenário de instabilidade política, foram utilizados por Rosas para desenvolver um governo bastante peculiar na região do Prata. Mesmo que o limite do poder do governador estivesse nas fronteiras da província de Buenos Aires, Rosas alcançou, principalmente a partir de 1840, a tão sonhada ordem política, desejo que a maioria das lideranças provinciais e da sociedade tinham desde 1810, através de uma política impositiva, violenta, justificada pela defesa da autonomia provincial, mas com intervenções concretas.

Apesar da política controversa e da pouca utilização de recursos políticos considerados tradicionais naquele contexto - como a Constituição -, foi na Sala de Representantes de Buenos Aires que Rosas conseguiu apoio político para suas ações internas e externas. Para isso, ao longo dos anos em que esteve no poder, procurou formar a Legislatura com nomes considerados confiáveis e leais, tanto à causa federal quanto a si próprio. A composição das Salas de Representantes de Buenos Aires foi se transformando ao passo que a causa federal se consolidava e, ao longo dos anos, a partir do material exposto pela autora, nota-se a presença de mais estancieiros e militares: o primeiro para garantir a estabilidade e o segundo, a legalidade.

Analisar e entender a formação dessa Legislatura anualmente e os movimentos desses atores - quem eram e quais relações eram estabelecidas -, é o ponto de partida da autora para mergulhar no mundo relacional de Rosas. A exposição de gráficos e tabelas com os nomes e as formações profissionais dos representantes presentes ao longo da

\footnotetext{
${ }^{1} \mathrm{O}$ título de Restaurador de las Leyes ganhou as ruas de Buenos Aires através do jornal de mesmo nome entre julho e outubro de 1833 tendo Pedro de Angelis, importante intelectual desse contexto, como editor. Ver mais em SCHELL, Deise Cristina (2018). Entre coleções e arquivos: produção de conjuntos documentais (Buenos Aires, 1835-1852). UFRGS: Tese de Doutorado.
} 
segunda parte do livro demonstram o esforço da autora em olhar o governo de Rosas de uma outra perspectiva: a partir de rostos ocultos, pouco presentes na História nacional, participantes da engrenagem política do governo rosista nos bastidores, disseminadores das ideias federais para além dos recursos oficiais. Ao personalizar a História desse governo, Reguera entende que Rosas se manteve no poder devido a essa vasta e complicada rede composta por advogados, fazendeiros, médicos, jornalistas, clérigos e militares.

Boa parte dessas relações foram estabelecidas por interesse político e com base em troca de favores. Esse tipo de construção de laços de confiança fez parte da vida de Rosas desde sua infância até parte de sua juventude ${ }^{2}$. Ao longo da análise sobre a família - e a complicada organização que a compunha, já que o casamento entre primos era frequente - Reguera destaca a aproximação de importantes sobrenomes da política portenha - como Maza, Anchorena, Belgrano -, o contato com líderes indígenas devido ao comércio da família de açúcar e erva mate e os encontros sociais - tertúlias - que ocorriam na estância da família. Essas reuniões sociais foram um traço mantido durante o governo rosista, com a diferença que, no desenvolvimento da política personalista de Rosas, esses encontros serviram para disseminar avisos, mensagens, piadas e fofocas entre os presentes com o intuito de conhecer os políticos, identificar os considerados inimigos e reforçar sua posição enquanto líder.

A formação do líder e de seu governo se tornou parte da dinâmica de sua casa e de sua vida pessoal com sua esposa Encarnación Ezcurra, importante nome na articulação da causa federal, principalmente durante o período em que Rosas esteve na campaña (1833-1834). As cartas trocadas com Rosas, com amigos e apoiadores apontam que ela foi a principal cabeça na formação da Sociedad Restauradora, associação de civis pela causa federal responsável pela Revolução de los Restauradores em 1833. Com relação a Manuelita, filha mais velha de Rosas, desde cedo também conviveu e se relacionou politicamente com importantes nomes de Buenos Aires, ajudando o pai a desenvolver a vida social enquanto governador, criando laços de amizade com a família Maza, Wilde e até mesmo com Juan Bautista Alberdi. Após o falecimento de Encarnación Ezcurra em 1838, Manuelita assumiu um lugar de importância no governo do pai, respondendo a inúmeras cartas de políticos, líderes locais, ministros, almirantes e pessoas comuns, que desejavam apenas saudar o governador de Buenos Aires.

\footnotetext{
${ }^{2}$ Devido a problemas com sua mãe, Rosas saiu de casa em meados de 1810 para construir sua fortuna.
} 
Para além da esfera familiar, sua reputação como chefe atencioso, próximo e garantidor de ações políticas contundentes veio dessa base de relações que nutria desde a juventude, mas também, e principalmente, de como se relacionava com seus empregados. Usando como referência os ensinamentos do pai e os negócios da família, logo investiu em fazendas e pouco tempo depois se tornou o fazendeiro que pagava melhor, que usava do tempo de ócio para estar com os mandatários, que apadrinhava alguns de seus empregados. Dessa forma criou uma imagem de líder próximo de seus liderados para além da esfera pessoal e, ao aplicar esse jeito de lidar com seus funcionários em outros setores de sua vida pública, desenvolveu mais ainda essa imagem em uma esfera maior.

Com esse traço de liderança e com outros elementos de cunho popular e material - divisa punzó, moedas, luvas, miniaturas, objetos com seu rosto; demonstração de apoio ao governo com vivas y mueras, missas de ação de graça, desfiles, festas, entre outros que se utilizou ao longo de seu governo, Rosas desenvolveu uma política personalista e gerou um certo fanatismo pela sua pessoa. Além disso, procurou construir a imagem do líder fruto da sociedade portenha ao utilizar-se de aparatos da cultura gaucha em sua vestimenta, fazendo com que houvesse reconhecimento pelas camadas mais baixas da sociedade. A ideia de introduzir esses elementos materiais e visuais era de plantar costumbres entre los paisanos para construir uma opinião popular sobre sua imagem.

Todo esse importante aparato social e relacional fez com que a estrutura de seu poder começasse e terminasse nele mesmo. $\mathrm{O}$ argumento da autora é que esse tipo de relação social - ou relações sociais - conferia mais garantia de que haveria obediência por parte dos civis, já que a criação da confiança se dá em pequenas atitudes e na forma como o líder se comunica com os diferentes grupos. Um bom exemplo disso é o ajuste de linguagem feito por Rosas: se a carta se direcionava a um comerciante, Rosas escrevia em mala ortografía, para os líderes indígenas, uma linguagem simples e direta, enquanto para os membros da elite e apoiadores políticos, o tom era respeitoso, modesto, educado. A importância do ajuste da fala para estabelecer vínculos adequados com os diferentes atores fez com que a devolutiva dessa relação fosse apoio, fidelidade, aproximação, concessão.

Ainda na chave da comunicação, o uso da imprensa também alimentou essas relações, a fim de acessar todos esses grupos de maneira oficial e pública. Vale destacar que no segundo governo a imprensa foi censurada por meio da Ley de Prensa de 1832, fazendo com que os diversos jornais criados a partir de 1820 fossem fechados sob a 
justificativa de serem inimigos de Rosas. O La Gaceta Mercantil se tornou o veículo oficial do governo rosista, a partir de 1835 com um editorial de ataque constante aos unitários, além de divulgação de notícias de Buenos Aires e das províncias, acontecimentos para além das fronteiras e decisões da Sala de Representantes. ${ }^{3}$

As estratégias de formação de sua imagem, a manutenção de certos comportamentos adquiridos desde o seio familiar e o uso de uma linguagem adequada promoviam afastamento do imaginário comum de um líder distante e cheio de honrarias. Mas a política rosista se consolidou em diálogo com vários setores sociais em diferentes escalas econômicas e políticas de forma a ser possível, ao longo de seu governo, a conquista de vários tipos de favores e acordos de confiança com esses grupos, dentre eles os grupos armados.

É comum identificar Rosas com o título de “coronel”, porém também é preciso ter em mente que, apesar de sua experiência como fazendeiro e na política, ele nunca se envolveu diretamente com os grupos militares ou participou dos conflitos pela Independência (1816) ou na Guerra contra o Brasil (1825-1828) ${ }^{4}$, mas a confiança e o respeito desses grupos se deram no período em que esteve na campaña (entre 1833 e 1834) chamando a atenção dos soldados e lideranças devido ao pensamento estratégico e a previsão para problemas.

A relação política e de poder com os militares se constituiu com ropas de los paisanos, na aproximação com os chefes de campaña e os ganaderos procurando entender suas demandas e interesses. Nesse campo das relações sociais e políticas, Reguera destaca dois pontos que favoreceram Rosas: o trato com as lideranças indígenas, presente na sua vida familiar graças ao comércio estabelecido com algumas comunidades por seu pai, que foi fundamental na ampliação das terras agrícolas ocupadas, e a organização de grupos de milicianos para o cercamento das terras, fazendo com que 600 homens se tornassem um regimento oficial em 1834 e inspirando a organização de $L a$ Mazorca, grupo armado fiel a Rosas e responsável por manter a ordem federal nos espaços públicos através da violência.

\footnotetext{
${ }^{3}$ Os unitários, em um primeiro momento, eram o grupo político contrário aos federais, que ganhou força com o governo de Bernardino Rivadavia (1826-1827); ao longo do segundo governo de Rosas, eram os considerados inimigos e culpados por toda crise e falta de desenvolvimento das províncias, sem que houvesse um filtro necessariamente político para essa "classificação". Ver mais em ZUBIZARRETA, Ignacio (2014). Unitários. Historia de la facción política que diseñó la Argentina Moderna. Buenos Aires: Editora Sudamericana.

${ }^{4} \mathrm{Na}$ historiografia brasileira, esse conflito tem o nome de Guerra da Cisplatina.
} 
O argumento da autora é que a formação dessas várias relações na construção do poder de Rosas fez com que ele permanecesse tanto tempo no poder sem aparatos políticos considerados legítimos, como a Constituição. Na prática, contou com o controle da imprensa, a violência armada, o discurso federal, a ampliação dos poderes, a eliminação do inimigo e da criação de uma esfera de tensão a partir de Buenos Aires para irradiar seu poder nas províncias, fazendo com que os governadores também se tornassem favoráveis à política rosista; caso contrário, seriam afastados da política, eliminados, exilados. Rosas construiu seu poder, portanto, a partir de uma rede política composta por grupos sociais fortes e capazes de serem fiéis à causa federal, mas também à sua pessoa.

Alguns conceitos são importantes na condução da análise da autora: laços, rede e sociabilidade. Sobre este último, Reguera destaca que a família cumpre esse papel em um primeiro momento e que os laços de amizade aparecem como desenvolvimento desse conceito na vida do indivíduo, bem como espaços de lazer. A política exerce esse papel por meio do partido e do compartilhamento ideológico e pode encontrar na sociabilidade patriótica uma ramificação de sua ação na prática; as relações diplomáticas também expressam sociabilidade, já que, naquele contexto, os jantares oferecidos pelos nomes das relações exteriores conferiam visibilidade aos participantes por meio da imprensa. Além disso, a relação de apadrinhamento - prática comum devido à cultura católica presente no Rio da Prata e desenvolvida principalmente pela elite - foi aprofundada no período rosista, já que estreitava a relação entre famílias.

Reguera destaca também relações de sociabilidade no espaço público como os cafés e os grupos civis, bem como o recurso epistolar, amplamente utilizado por Rosas para comunicar-se e, em alguns casos, interferir na política dos governadores de províncias. Se no segundo mandato boa parte das associações civis foram suspensas sob a justificativa de organização unitária - e por isso inimiga - e esse tipo de sociabilidade era amplamente vigiada pelo grupo armado La Mazorca, as diversas cartas trocadas entre Rosas e os governadores das províncias serviram para encurtar as distâncias, controlar a política das províncias, manter os laços com os governadores, fortalecer a rede política estabelecida e conseguir apoio em suas ações disseminando fofocas, fazendo barganhas e impondo medidas federais.

O recurso epistolar foi utilizado por Rosas até o final de sua vida em 1877, quando já estava no exílio em Southampton, Inglaterra. Após sua queda na Batalha de Caseros em 1852, Rosas assinou sua abdicação ao posto de governador e, entendendo que parte 
de sua rede já não o apoiava devido ao crescimento político de Justo José de Urquiza, governador de Entre Ríos, partiu para o solo inglês com Manuelita, sua filha, levando aproximadamente 19 caixas de documentos, cartas e ofícios. De lá, manteve contato com membros da família, com sua amiga de infância Josefa Gómez, recebeu a visita de amigos, adversários e conhecidos até seu falecimento. $\mathrm{O}$ exílio político do homem que procurou formar seu poder através de uma complicada trama de relações sociais e políticas permite pensar nas consequências desse tipo de relação pouco profunda, baseada apenas em interesses políticos e favores.

A historiografia da época de Rosas é vasta, composta por inúmeros estudos em diferentes pontos desse governo. Os recursos da história social e da micro-história tornam o trabalho de Andrea Reguera um material necessário para o estudo a partir de um outro olhar sobre esse importante período histórico, conferindo personalismo à construção do poder e entendendo os diferentes atores políticos como componentes da engrenagem desse governo. Destaca-se o trabalho intenso de levantamento desses nomes, a utilização das várias cartas para embasar o argumento e a busca por um discurso historiográfico que, em um primeiro momento, pode parecer biográfico, mas que é ampliado ao longo da leitura.

Artigo recebido em 01 de abril 2021.

Aprovado em 18 de junho de 2021.

\author{
Juliana da Silva Sabatinelli \\ Doutoranda em História Política pela UERJ \\ ju.sabatinelli@gmail.com
}

DOI: 10.12957/intellectus.2021.57641 